\title{
MECANISMOS DE REGENERAÇÃO NATURAL EM REMANESCENTE DE FLORESTA OMBRÓFILA MISTA, RS, BRASIL
}

\author{
Angela Luciana de Avila1*, Maristela Machado Araujo², Ezequiel Gasparin³, Solon Jonas Longhi ${ }^{3}$ \\ *Autora para correspondência: angela.de.avila@waldbau.uni-freiburg.de
}

RESUMO: Neste estudo, objetivou-se caracterizar os mecanismos de regeneração natural em um remanescente de Floresta Ombrófila Mista. O trabalho foi realizado na Floresta Nacional de São Francisco de Paula, RS, Brasil, utilizando seis conglomerados de 1 ha, com 16 parcelas $(20 \times 20 \mathrm{~m})$ cada, desconsiderando $10 \mathrm{~m}$ de bordadura. A amostragem da chuva de sementes (CS) foi realizada em 96 coletores circulares $\left(1 \mathrm{~m}^{2}\right)$, distribuídos no centro de cada parcela. O banco de sementes do solo (BS) foi amostrado de forma aleatória, a $3 \mathrm{~m}$ de cada coletor da CS, e o banco de plântulas (BP) foi amostrado em subparcelas de $2 \times 2 \mathrm{~m}$, alocadas a $4 \mathrm{~m}$ dos coletores, contabilizando o número de indivíduos (altura $\geq 30 \mathrm{~cm}$ e diâmetro à altura do peito (DAP) $<1 \mathrm{~cm}$ ) para cada espécie. Os mecanismos de regeneração foram avaliados quanto à composição florística e estrutura horizontal. Na CS, foram amostradas 81 espécies, 46 gêneros e 28 famílias, no BS, 103, 65 e 41 e no BP, 88, 57 e 36, respectivamente. A riqueza encontrada e abundante frutificação de espécies com dispersão zoocórica indicam a importância da chuva de sementes como mecanismo estratégico para o equilíbrio da fauna e flora no ecossistema. O banco de sementes do solo demonstra potencial para colonização imediata e restabelecimento da vegetação após perturbações e o banco de plântulas consiste na principal estratégia de regeneração de muitas espécies arbóreas que compõe a atual estrutura da floresta.

Palavras-chave: Chuva de sementes, banco de sementes do solo, banco de plântulas.

\section{NATURAL REGENERATION MECHANISMS IN MIXED SUBTROPICAL WET FOREST REMNANT, RS, BRAZIL}

\begin{abstract}
This study aimed to characterize the mechanisms of natural regeneration in a Mixed Subtropical Wet Forest remnant. The study was conducted in the National Forest of São Francisco de Paula, RS, Brazil, using six conglomerates (1 ha), with 16 plots $(20 \times 20 \mathrm{~m})$ each, disregarding $10 \mathrm{~m}$ surround. The sampling of the seed rain (SR) was carried out in 96 circular collectors $\left(1 \mathrm{~m}^{2}\right)$, distributed in the center of each plot. The soil seed bank $(S B)$ was sampled randomly in a distance of $3 \mathrm{~m}$ of each SR collector and the seedling bank $(\mathrm{SeB})$ was sampled in plots of $2 \times 2 \mathrm{~m}$, located $4 \mathrm{~m}$ from SR collectors, counting the number of individuals (height $\geq$ $30 \mathrm{~cm}$ and diameter at breast height $(D B H)<1 \mathrm{~cm})$ for each species. The regeneration mechanisms were evaluated through the floristic composition and horizontal structure. In SR, were sampled 81 species, 46 genera and 28 families, in SB, 103, 65 and 41, and in $\mathrm{SeB}, 88,57$ and 36, respectively. The richness found and the presence of species with abundant fruiting and seed dispersal by animals, indicate the importance of seed rain as a strategic mechanism for the balance of flora and fauna in the ecosystem. The soil seed bank demonstrates potential for colonization and immediate restoration of vegetation after disturbances and the seedling bank is the main strategy for regeneration of many tree species that make up the current structure of the forest.
\end{abstract}

Key words: Seed rain, seed bank, seedling bank.

\section{INTRODUÇÃO}

Os ecossistemas florestais exercem função ambiental e social, pois abrigam grande diversidade, propiciando a conservação de espécies, manutenção do fluxo gênico e dos processos evolutivos. Além disso, resguardam espécies medicinais, protegem o solo, regulam o clima, fornecendo alimento e recursos florestais ao homem, entre outros benefícios. No entanto, ao mesmo tempo em que se identifica a relevante importância das florestas, também se observa um processo adiantado de alteração e degradação.

A Floresta Ombrófila Mista, no Rio Grande do Sul, durante muito tempo passou pela exploração não sustentável dos recursos florestais associada à conversão no uso da terra. Esse tipo florestal teve uma redução de, aproximadamente, $81 \%$ em sua área de distribuição e entre os fatores responsáveis por essa alteração encontra-se a forte pressão sobre as populações naturais de Araucaria angustifolia (Bertol.) Kuntze (pinheiro-brasileiro) e outras espécies de valor comercial (RIO GRANDE DO SUL, 2002).

A exploração irracional dos recursos, conversão na forma de uso da terra e fragmentação continuam ameaçando o equilíbrio das florestas naturais. Diante disso, a pesquisa científica faz-se necessária para gerar informações sobre a dinâmica desses ecossistemas, permitindo o estabelecimento de práticas que visem a

\footnotetext{
${ }^{1}$ Universidade de Freiburg - Freiburg, Alemanha

${ }^{2}$ Universidade Federal de Santa Maria - Santa Maria, Rio Grande do Sul, Brasil

${ }^{3}$ Universidade Federal de Lavras - Lavras, Minas Gerais, Brasil
}

Cerne, Lavras, v. 19, n. 4, p. 621-628, out./dez. 2013 
sua conservação, recuperação e uso sustentável. Begon et al. (2007) descreveram que a manutenção de espécies ameaçadas e a restauração podem ser favorecidas por práticas embasadas no conhecimento sobre o processo de renovação da floresta e, segundo Carvalho (1997), o conhecimento sobre a dinâmica da regeneração é um dos pressupostos para um sistema silvicultural baseado na regeneração natural.

A forma como a floresta se regenera depende de mecanismos que viabilizem o ingresso e o estabelecimento de novos indivíduos e espécies, como a chuva de sementes, banco de sementes do solo e banco de plântulas. Segundo Alvarez-Buylla e Martínez-Ramos (1990), a permanência de uma espécie, em determinado ecossistema, depende de seu sucesso no processo de colonização, o qual é influenciado pelas características na dispersão e longevidade das sementes.

Assim, a chuva e o banco de sementes constituem importante fonte de diásporos para o recrutamento de novos indivíduos e espécies nos ecossistemas terrestres (GROMBONE-GUARATINI; RODRIGUES, 2002). O banco de plântulas tem sua origem nas sementes recémdisseminadas ou persistentes no banco de sementes do solo, possibilitando o recrutamento para estágios de desenvolvimento mais avançados (BAZZAZ, 1991).

O conhecimento sobre os mecanismos de regeneração natural em ecossistemas florestais no sul do Brasil é restrito a alguns trabalhos (ARAUJO et al., 2004; CALDATO et al., 1996; LONGHI et al., 2005; SCHERER; JARENKOW, 2006). Assim, considerando a pressão incidente sobre os ecossistemas florestais e a consequente demanda por práticas que possibilitem a conservação de espécies, o uso sustentável e a recuperação ambiental das florestas nativas, no presente estudo, objetivou-se avaliar os mecanismos de regeneração natural (chuva de sementes, banco de sementes do solo e banco de plântulas), buscando caracterizar a sua participação no processo regenerativo de um remanescente de Floresta Ombrófila Mista, RS, Brasil.

\section{MATERIAL E MÉTODOS}

\section{1 Área de estudo}

A Floresta Nacional de São Francisco de Paula (FLONA-SFP) situa-se na região nordeste do Rio Grande do Sul, Brasil. Possui área correspondente a 1.606,6 ha, com cerca de $56 \%$ ocupado por florestas naturais. A máxima altitude é de, aproximadamente, $930 \mathrm{~m}$ (BRASIL, 2000). Os solos da região são do tipo Cambissolo Húmico
Alumínico Típico - CHa 1 (EMPRESA BRASILEIRA DE PESQUISA AGROPECUÁRIA - EMBRAPA, 1999), comum em locais onde ocorre elevada precipitação e baixas temperaturas, que favorecem o acúmulo de matéria orgânica.

O clima, conforme classificação de Köppen é do tipo "Cfb" (mesotérmico e superúmido), com chuvas distribuídas ao longo do ano e temperatura média do mês mais quente, inferior a $22^{\circ} \mathrm{C}$, e do mês mais frio, superior a $3{ }^{\circ} \mathrm{C}$ (MORENO, 1961). A precipitação média anual situa-se em torno de $2.500 \mathrm{~mm}$ (NIMER, 1990).

O tipo florestal característico é a Floresta Ombrófila Mista (FOM), que apresenta o pinheiro-brasileiro como espécie dominante e emergente, acompanhado por espécies de Lauraceae como Ocotea puberula (Rich.) Nees e Nectandra megapotamica (Spreng.) Mez, entre outras. No estrato inferior apresenta predominância de espécies de Myrtaceae (QUADROS; PILLAR, 2002; RODERJAN et al., 2002).

\subsection{Amostragem dos dados}

A pesquisa utilizou parte da estrutura amostral do Projeto PELD/CNPq (Projeto Ecológico de Longa Duração). Foram utilizados seis conglomerados $(100 \times 100 \mathrm{~m})$, desconsiderando $10 \mathrm{~m}$ de bordadura e dividindo-os em 16 parcelas de $20 \times 20 \mathrm{~m}$. A amostragem da chuva de sementes, banco de sementes do solo e banco de plântulas, foi realizada tomando como base o centro de cada parcela como referência.

A chuva de sementes (CS) foi avaliada em 96 coletores circulares $\left(1 \mathrm{~m}^{2}\right)$, dispostos no centro de cada parcela. As coletas foram realizadas mensalmente (fevereiro de 2008 a janeiro de 2009), sendo o material armazenado em sacos plásticos, previamente identificados com o número do coletor e conduzidos ao Laboratório de Silvicultura (Universidade Federal de Santa Maria UFSM) para a triagem das sementes aparentemente viáveis e com tamanho igual ou maior que $1 \mathrm{~mm}$. A quantificação foi realizada por meio de contagem e para sementes muito pequenas e/ou depositadas em grande quantidade, por meio da determinação do peso de mil sementes (BRASIL, 2009).

O banco de sementes (BS) foi amostrado a $3 \mathrm{~m}$ dos coletores da CS, em sentido aleatório, por meio de um gabarito de ferro $(0,25 \times 0,25 \mathrm{~m})$, coletando-se os primeiros $5 \mathrm{~cm}$ do solo, desconsiderando a camada de serapilheira. A coleta foi realizada em outubro de 2008. O material, armazenado em saco plástico e identificado, foi conduzido para a casa de vegetação com o objetivo de estimular

Cerne, Lavras, v. 19, n. 4, p. 621-628, out./dez. 2013 
a germinação. Para tal, cada uma das 96 amostras, foi espalhada no interior de uma bandeja com $3 \mathrm{~cm}$ de vermiculita, as quais foram distribuídas aleatoriamente sobre bancadas, cobertas com tela de náilon $(50 \%$ de sombreamento) para evitar a contaminação de propágulos externos. A verificação de possíveis contaminantes foi realizada pelo uso de quatro bandejas testemunhas (ARAUJO et al., 2004; HALL; SWAINE, 1980).

O estudo do BS foi conduzido durante sete meses, com irrigação e monitoramento diários. A identificação e contagem das plântulas germinadas foram realizadas mensalmente. A análise fisionômica da vegetação presente nesse mecanismo pode ser realizada por meio da identificação das formas de vida: árvore (vegetal lenhoso, com altura mínima de $5 \mathrm{~m}$ e fuste simples até a ramificação da copa); arbusto (vegetal lenhoso, com altura menor que $5 \mathrm{~m}$ e ramificado desde a base); erva (vegetal não-lignificado e comumente anual); liana (vegetal com hábito sarmentoso) (FONT QUER, 1979). Os graminóides foram contabilizados como ervas e as trepadeiras como lianas e quando não encontrada descrição na literatura as sementes germinadas foram classificadas na categoria "sem informação" (Figura 2a). No sexto mês, considerando a redução na densidade de sementes germinadas, foi realizado o revolvimento, buscando estimular a germinação de sementes remanescentes.

A avaliação do banco de plântulas ocorreu em março de 2009, utilizando 96 subparcelas de $2 \times 2 \mathrm{~m}$, localizadas em sentido aleatório e a $4 \mathrm{~m}$ do coletor da CS. Nesse mecanismo, foram amostrados os indivíduos de espécies arbóreas e arbustivas com altura igual ou maior que $30 \mathrm{~cm}$ e diâmetro a $1,3 \mathrm{~m}$ do solo (diâmetro à altura do peito - DAP) menor que $1 \mathrm{~cm}$, realizando a contagem do número de indivíduos por espécie.

A identificação das espécies, em todos os mecanismos, quando possível, foi realizada in loco ou por meio de busca na literatura ilustrada, semeadura e transplante, confecção de exsicatas, consulta a especialistas e aos Herbários do Departamento de Ciências Florestais (HDCF)/UFSM e do Instituto de Ciências Naturais da Universidade Federal do Rio Grande do Sul (ICN/ UFRGS). No entanto, em casos que a classificação não foi possível, as mesmas foram denominadas morfoespécies, considerando a planta apresentar-se com morfologia diferente das demais. A nomenclatura das espécies segue a proposta do APG II (ANGIOSPERM PHILOGENENY GROUP, 2002 apud SOBRAL et al., 2006; SOUZA; LORENZI, 2005).

\subsection{Análise dos dados}

Os mecanismos de regeneração foram descritos quanto à composição florística, índice de diversidade de Shannon (H') e equabilidade, que indica a uniformidade na distribuição dos indivíduos entre as espécies (BROWER; ZAR, 1977), sendo também analisados os valores de densidade. A similaridade foi analisada entre os três mecanismos, considerando as espécies arbóreo e arbustivas.

Além disso, a CS foi caracterizada quanto à composição florística, síndromes de dispersão (SD), densidade de sementes disseminadas ao longo do tempo e períodos de frutificação. No BS, foi analisada a florística, forma de vida $(\mathrm{FV})$ e a porcentagem de sementes germinadas no tempo. Em todos os mecanismos, foi registrado o grupo ecológico (GE) das espécies pertencentes à forma de vida árvore e arbusto, que obtiveram identificação completa, seguindo a classificação proposta por Budowski (1965): pioneira (Pi), secundária inicial (Si), secundária tardia $(\mathrm{St})$ e clímax $(\mathrm{Cl})$. A SD, FV e GE foram obtidos com base em revisão bibliográfica em literatura especializada.

A avaliação da suficiência amostral para o banco de plântulas foi realizada por meio da análise gráfica na curva espécie-área (número acumulado de espécies $\mathrm{x}$ área amostrada). Segundo McCune e Mefford (1999), a mesma permite identificar se a amostragem foi suficiente para representar as variações existentes na comunidade.

\section{RESULTADOS E DISCUSSÃO}

$\mathrm{Na}$ chuva de sementes foram amostradas 81 espécies, pertencentes a 46 gêneros e 28 famílias. Entre essas, 52 tiveram classificação completa, quatro em nível gênero, quatro ao de família, não se obtendo identificação para 21, assim, denominando-as de morfoespécies. As famílias com maior riqueza, nesse mecanismo, foram: Myrtaceae (9 espécies), Fabaceae (6), Sapindaceae (5) e Lauraceae (5). Estas também foram observadas como predominantes na CS, em fragmentos de Floresta Atlântica, em São Paulo, por Pivello et al. (2006).

Tabarelli e Peres (2002) relataram que as famílias Myrtaceae e Lauraceae demonstram grande interação com a fauna, sendo que, a dispersão de sementes e o recrutamento das plantas estão diretamente relacionados com a permanência e conservação da fauna dispersora. Assim, essa afirmação confirma o papel das espécies-chave na chuva de sementes, como fonte de alimento para a fauna, o que constitui estreita relação entre a conservação de espécies animais e vegetais.

Cerne, Lavras, v. 19, n. 4, p. 621-628, out./dez. 2013 
Nesse contexto, considerando as síndromes de dispersão no remanescente, foram identificadas $65 \%$ das espécies com dispersão zoocórica e 17\% anemocórica. A grande presença de espécies dispersadas pela fauna é comumente observada em estudos sobre a CS, conforme pode ser observado nos trabalhos desenvolvidos por Loiselle et al. (1996) em uma floresta tropical da Costa Rica e Pivello et al. (2006) na Floresta Atlântica, São Paulo, Brasil. Pinheiro e Ribeiro (2001) relataram que isso ocorre, porque a maior parte das espécies florestais tropicais interage com a fauna no processo de dispersão das sementes. A classificação em grupos ecológicos indicou maior proporção de espécies "iniciais" $(40 \%)$ (pioneiras e secundárias iniciais) em relação a "tardias" (30\%) (secundárias tardias e clímax).

A densidade de diásporos dispersados na área, durante doze meses, foi 1.193 sementes $\mathrm{m}^{-2}$. Ilex brevicuspis Reissek, Blepharocalyx salicifolius (Kunth) O. Berg, Ilex paraguariensis A. St.-Hil. e Vernonia discolor (Spreng.) Less. somaram 83\% desse valor. A diversidade (H') estimada foi de 1,99 e a equabilidade 0,45 , refletindo o comportamento de predomínio de poucas espécies com elevada densidade.

A análise temporal indicou que, de fevereiro a maio, houve grande intensidade de dispersão de diásporos, diminuindo posteriormente e voltando a aumentar em dezembro, quando teve início o período de frutificação de Vernonia discolor, a qual somou $90 \%$ do total de sementes depositadas nesse mês (Figura 1).

Os meses de agosto a novembro correspondem a um período crítico na disponibilidade de alimento para a

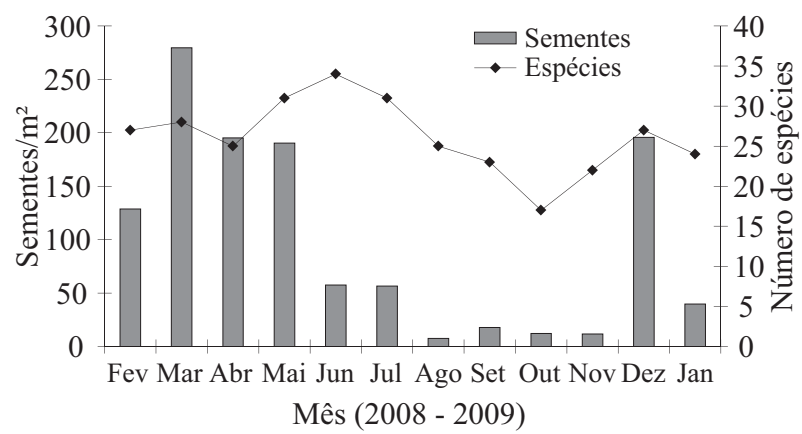

Figura 1 - Quantidade de sementes e espécies dispersadas, durante 12 meses, em remanescente de Floresta Ombrófila Mista, São Francisco de Paula, RS, Brasil.

Figure 1 - Number of species and seeds dispersed, during 12 months, in a Mixed Subtropical Wet Forest remnant, São Francisco de Paula, RS, Brazil.

Cerne, Lavras, v. 19, n. 4, p. 621-628, out./dez. 2013 fauna frugívora. Resultados semelhantes foram observados por Araujo et al. (2004), estudando esse mecanismo em mata ciliar de Floresta Estacional Decidual, no Rio Grande do Sul, onde encontraram maior dispersão de propágulos entre abril e maio. Campos et al. (2009), em Floresta Estacional Semidecidual, em Minas Gerais, observaram maior concentração de sementes em fevereiro e março.

No banco de sementes do solo, foram encontradas 103 espécies, distribuídas em 65 gêneros e 41 famílias. Entre estas, 75 foram identificadas ao nível específico, 20 em nível de gênero, duas no de família e seis não foram identificadas. A diversidade (H') encontrada para esse mecanismo foi de 2,98, com equabilidade de 0,64 , indicando representatividade heterogênea das espécies.

As famílias Asteraceae e Solanaceae apresentaram 31 e 12 espécies, respectivamente, estando entre as cinco $\left(1^{\mathrm{a}}\right.$ e $\left.5^{\mathrm{a}}\right)$ com maior número de sementes germinadas. A predominância das mesmas, tanto na abundância quanto na composição florística, também foi observada por Wijdeven e Kuzze (2000) no BS de floresta tropical, na Costa Rica. Liebsch e Acra (2004) identificaram o predomínio de Asteraceae e Solanaceae na vegetação de sub-bosque de áreas de capoeira e trilhas em regeneração, em FOM, Tijucas do Sul, no PR, indicando a associação dessas famílias com o mecanismo do BS para colonização imediata após perturbações.

Aquifoliaceae foi a sexta família com maior densidade (34 sementes $\mathrm{m}^{-2}$ ), representada por duas espécies (Ilex brevicuspis e Ilex paraguariensis), sendo essas as mais representativas da forma de vida árvore. A relevante participação dessa família no banco de sementes do solo está associada à elevada produção de sementes, ao mesmo tempo, em que as espécies apresentam dormência morfológica, pela imaturidade do embrião, necessitando um período de baixas temperaturas e alta umidade, para completar seu desenvolvimento (BORGHETTI, 2004). Assim, as mesmas permanecem no solo, enquanto completam sua maturação, aguardando também condições favoráveis à germinação.

As herbáceas somaram $80 \%$ do total de sementes germinadas, seguidas por árvores (8\%) e arbustos $(6,7 \%)$ (Figura 2a). Esse porcentual condiz com resultados encontrados em outros estudos, onde as ervas também predominaram no banco de sementes do solo (ARAUJO et al., 2004; BATISTA NETO et al., 2007). Segundo Araujo et al. (2004), as espécies herbáceas são fundamentais no processo de sucessão, sendo os primeiros elementos de colonização em áreas perturbadas. 

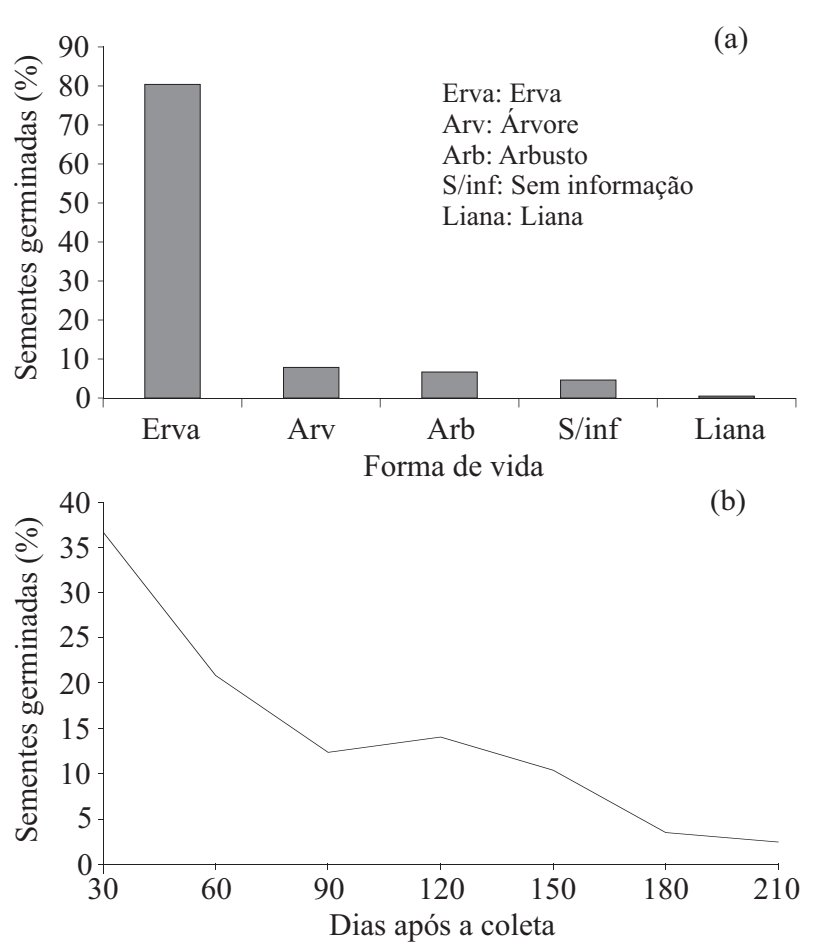

Figura 2 - Porcentagem de sementes germinadas por forma de vida (a) e ao longo de 210 dias de avaliação (b), em remanescente de Floresta Ombrófila Mista, RS, Brasil.

Figure 2 - Percentage of seeds germinated by life form (a) and over 210 days of evaluation (b), in a Mixed Subtropical Wet Forest remnant, RS, Brazil.

A densidade de sementes germinadas foi de 868 sementes $\mathrm{m}^{-2} \mathrm{e}$ a maior proporção foi observada no primeiro mês (Figura 2b). Batista Neto et al. (2007) registraram 949 sementes $\mathrm{m}^{-2}$, em Floresta Estacional Semidecidual, em Minas Gerais. Após o revolvimento das amostras (180 dias), observou-se que a germinação continuou decrescendo. Aos 30 dias, foi observada grande abundância de sementes germinadas de espécies pertencentes às famílias Asteraceae e Cyperaceae. Entre as primeiras espécies arbóreas e arbustivas amostradas, destacaramse Sapium glandulosum (L.) Morong, Zanthoxylum rhoifolium Lam. e Solanum mauritianum Scop., as quais pertencem ao grupo ecológico das pioneiras.

A espécie Ilex paraguariensis foi observada pela primeira vez aos 60 dias e Ilex bevicuspis aos 120, sendo que, ambas, permaneceram germinando até 180 dias. As mesmas podem ter completado a maturação do embrião sob condição de estratificação no solo, pois a umidade foi mantida pela irrigação.
No banco de plântulas foram amostradas 88 espécies, pertencentes a 57 gêneros e 36 famílias botânicas. A família com maior riqueza de espécies foi Myrtaceae (18), seguida de Lauraceae (10), Salicaceae e Solanaceae (5). A predominância, quanto ao número de espécies, das famílias Myrtaceae e Lauraceae também foi registrada em outros estudos sobre a flora regenerante, de espécies arbóreas e arbustivas, em Floresta Ombrófila Mista (CALDATO et al., 1996; NARVAES et al., 2005), sendo também observada a relevante importância de ambas na vegetação adulta desse tipo florestal (ARAUJO et al., 2010; NASCIMENTO et al., 2001).

A análise da curva espécie-área indicou que a amostragem foi satisfatória para representar a composição florística do banco de plântulas, pois segundo Brower e Zar (1977), o número de amostras é considerado suficiente quando a curva tende a estabilização. Dessa forma, observa-se que, a partir de 65 subparcelas, $94 \%$ das espécies já haviam sido inventariadas, ocorrendo pequeno acréscimo até a totalização da área amostrada (Figura 3).

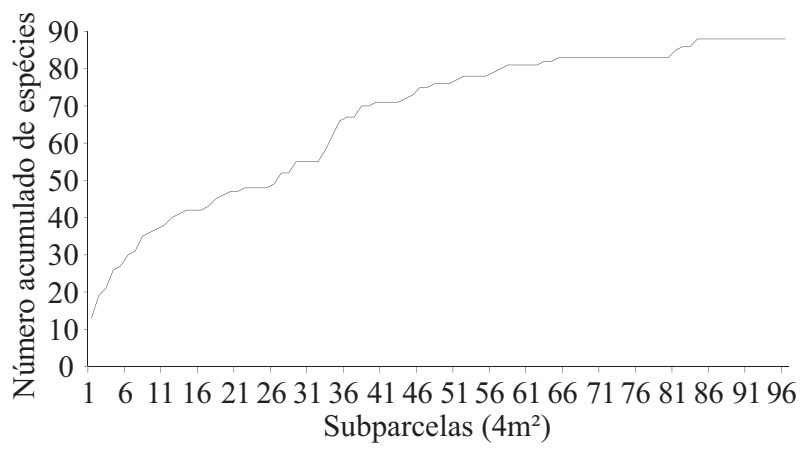

Figura 3 - Curva espécie-área para o banco de plântulas, em remanescente de Floresta Ombrófila Mista, São Francisco de Paula, RS, Brasil.

Figure 3 - Species-area curve for the seedling bank, in a Mixed Subtropical Wet Forest remnant, São Francisco de Paula, RS, Brazil.

A estimativa da diversidade (H') para o banco de plântulas foi de 3,06 , sendo superior a encontrada $(2,22)$ no estudo realizado por Narvaes et al. (2005), para regeneração entre 3 e $30 \mathrm{~cm}$ de circunferência à altura do peito (CAP), no mesmo remanescente. Por outro lado, Araujo et al. (2010) identificaram para a vegetação com $\mathrm{CAP} \geq 30 \mathrm{~cm}$ maior diversidade $(3,61)$. Nesse contexto, a equabilidade encontrada para o BP foi 0,68 , o que indica que poucas espécies concentraram grande parte dos indivíduos amostrados, influenciando no menor valor de H', se comparado com a vegetação adulta.

Cerne, Lavras, v. 19, n. 4, p. 621-628, out./dez. 2013 
A análise dos grupos ecológicos indicou que $30 \%$ das espécies foram classificadas como pioneiras ou secundárias iniciais e $40 \%$ como secundárias tardias ou clímax. Araujo et al. (2010) encontraram grande presença de espécies de estádios iniciais na vegetação adulta, o que deve estar mantendo contínua fonte de propágulos para a regeneração e continuidade dessas espécies no ecossistema, até que as condições do hábitat modifiquemse e favoreçam outros grupos ecológicos.

A densidade encontrada no BP foi de 51.406 indivíduos $\mathrm{ha}^{-1}$. As famílias Monimiaceae, Myrtaceae, Sapindaceae e Euphorbiaceae, em ordem decrescente, somaram $66 \%$ da densidade, com mais de 5.000 indivíduos ha $^{-1}$ cada uma. As espécies com maior abundância foram: Mollinedia elegans Tul. (16.640 indivíduos ha-1), Stillingia oppositifolia Baill. ex Müll.Arg. (4.557), Matayba elaeagnoides Radlk. (3.828), Piper xylosteoides (Kunth) Steud. (2.344), Casearia decandra Jacq. (1.667) e Myrcengenia oxysepala (Burret) D. Legrand \& Kausel (1.641).

Assim, observa-se que Monimiaceae, representada por uma única espécie (Mollinedia elegans), foi responsável por cerca de $32 \%$ da densidade de indivíduos. Segundo Peixoto et al. (2001), essa espécie adapta-se a ambientes com luz difusa e não apresenta exigências pronunciadas quanto às condições edáficas, o que favorece sua ampla distribuição e abundância no subbosque. Além disso, espécies da família Monimiaceae são descritas por apresentarem brotação (SANTOS; PEIXOTO, 2001), mecanismo observado para Mollinedia elegans, o que pode ter elevado sua densidade na área estudada, considerando a dificuldade de diferenciação em campo, entre a plântula oriunda de sementes e brotação de raízes.

A Araucaria angustifolia, espécie característica da FOM, apresentou 78 indivíduos ha ${ }^{-1}$ no BP, pertencendo ao grupo de espécies com menor densidade. Esse fato está associado, principalmente, às exigências ecológicas do pinheiro-brasileiro que, sendo heliófila, requer luminosidade para que a regeneração ocorra. Diversos estudos observaram comportamento semelhante, quanto às lacunas no processo de regeneração da espécie (CALDATO et al., 1996; NARVAES et al., 2005; SOUZA et al., 2008).

A maior similaridade florística (Índice de Sorensen) ocorreu entre a chuva de sementes e o banco de plântulas $(51 \%)$ e a menor entre o banco de sementes e o banco de plântulas (23\%). Esse fato corrobora a relação existente entre a dispersão dos diásporos e a atual composição florística da flora regenerante, sendo esses mecanismos essenciais para a conservação da floresta diante do atual estágio sucessional. Por outro lado, o banco de sementes do solo também consiste em mecanismo chave no ecossistema, pois permitirá desencadear o processo de sucessão diante de algum distúrbio, seja este de origem natural ou antrópica.

\section{CONCLUSÕES}

Os resultados da pesquisa permitem concluir que: - a chuva de sementes mostra potencial para manter a dinâmica do processo de regeneração das espécies florestais que compõe a atual estrutura da floresta;

- a grande riqueza florística e a presença de famílias e espécies que frutificam de forma abundante, como Blepharocalyx salicifolius e Ilex paraguariensis, indicam a importância da chuva de sementes como fonte de alimento para a fauna do ecossistema, contribuindo assim para seu equilíbrio;

- o banco de sementes do solo demonstra potencial para colonização imediata da área após perturbações, principalmente, com espécies herbáceas;

- o banco de plântulas demonstra ser a principal estratégia de regeneração de muitas espécies, interagindo continuamente com a CS que proporciona o aporte de propágulos necessários para a sua renovação.

\section{AGRADECIMENTOS}

Os autores agradecem ao professor Doádi Antônio Brena e ao projeto PELD - Subprojeto FLONA de São Francisco de Paula pelo suporte logístico. Aos colegas Régis Longhi, Marcelo Krug e Ângelo Ebling, pelo auxílio na coleta de dados e aos revisores que contribuíram anonimamente com o trabalho. Ao Conselho Nacional de Desenvolvimento Científico e Tecnológico-CNPq, pela concessão de bolsa de mestrado.

\section{REFERÊNCIAS}

ALVAREZ-BUYLLA, E. R.; MARTÍNEZ-RAMOS, M. Seed bank versus seed rain in the regeneration of a tropical pioneer tree. Oecologia, Berlin, v. 84, p. 314-325, 1990.

ARAUJO, M. M.; CHAMI, L.; LONGHI, S. J.; AVILA, A. L. de; BRENA, D. A. Analise de agrupamento em remanescente de Floresta Ombrófila Mista. Ciência Florestal, Santa Maria, v. 20, n. 1, p. 1-18, jan./mar. 2010.

Cerne, Lavras, v. 19, n. 4, p. 621-628, out./dez. 2013 
ARAUJO, M. M.; LONGHI, S. J.; BARROS, P. L. C. de; BRENA, D. A. Caracterização da chuva de sementes, banco de sementes do solo e banco de plântulas em Floresta Estacional Decidual ripária, Cachoeira do Sul, RS, Brasil. Scientia Forestalis, Piracicaba, n. 66, p. 128-141, 2004.

BATISTA NETO, J. P.; REIS, M. G. F.; REIS, G. G. dos; SILVA, A. F. da; CACAU, F. V. Banco de sementes do solo em uma Floresta Estacional Semidecidual, em Viçosa, MG. Ciência Florestal, Santa Maria, v. 17, n. 4, p. 311-320, 2007.

BAZZAZ, F. A. Regeneration of tropical forests: physiological responses of Pioneer and secondary species. In: GÓMEZPOMPA, A.; WHITMORE, T. C.; HADLEY, M. (Ed.). Rain forest regenaration and management. Paris: UNESCO, 1991. p. 91-118.

BEGON, M.; TOWNSEND, C. R.; HARPER, J. L. Ecologia: de indivíduos a ecossistemas. 4. ed. Porto Alegre: Artmed, 2007. $752 \mathrm{p}$.

BORGHETTI, F. Dormência embrionária. In: FERREIRA, A. G.; BORGHETTI, F. (Ed.). Germinação: do básico ao aplicado. Porto Alegre: Artmed, 2004. p. 109-124.

BRASIL. Floresta nacional de São Francisco de Paula, RS. Brasília: IBAMA, 2000. 6 p.

BRASIL. Ministério da Agricultura, Pecuária e Abastecimento. Regras para análise de sementes. Brasília, 2009. $395 \mathrm{p}$.

BROWER, J. E.; ZAR, J. H. Field and laboratory methods for general ecology. $2^{\text {nd }}$ ed. Iowa: Brown, 1977. $194 \mathrm{p}$.

BUDOWSKI, G. N. Distribution of tropical American rain forest species in the Light of sucesión processes. Turrialba, San José, v. 15, n. 2, p. 40-52, 1965.

CALDATO, S. L.; FLOSS, P. A.; CROCE, D. M. da; LONGHI, S. J. Estudo da regeneração natural, banco de sementes e chuva de sementes na reserva genética florestal de Caçador, SC. Ciência Florestal, Santa Maria, v. 6, n. 1, p. 27-38, 1996.

CAMPOS, E. P.; VIEIRA, M. F.; SILVA, A. F. da; MARTINS, S. V.; CARMO, F. M. S.; MOURA, V. M.; RIBEIRO, A. S. S.
Chuva de sementes em Floresta Estacional Semidecidual em Viçosa, MG, Brasil. Acta Botanica Brasilica, São Paulo, v. 23, n. 2, p. 451-458, 2009.

CARVALHO, J. O. P. Dinâmica de Florestas Naturais e sua implicação para o manejo florestal. In: CURSO DE MANEJO FLORESTAL SUSTENTÁVEL, 1., 1997, Curitiba. Anais... Colombo: EMBRAPA-CNPF, 1997. p. 43-55. (Documentos, $34)$.

EMPRESA BRASILEIRA DE PESQUISA

AGROPECUÁRIA. Centro Nacional de Pesquisa de Solos. Sistema brasileiro de classificação de solos. Brasília, 1999. $412 \mathrm{p}$.

FONT-QUER, P. Diccionario de botánica. Barcelona: Labor, 1979.

GROMBONE-GUARATINI, M. T.; RODRIGUES, R. R. Seed bank and seed rain in a seasonal semi-deciduous forest in south-eastern Brazil. Journal of Tropical Ecology, Cambridge, v. 18, n. 1, p. 759-771, 2002.

HALL, J. B.; SWAINE, M. B. Seed stocks in Ghanaian Forest soil. Biotropica, Marburg, v. 12, n. 4, p. 256-263, 1980.

LIEBSCH, D.; ACRA, L. A. Riqueza de espécies de subbosque de um fragmento de Floresta Ombrófila Mista, em Tijucas do Sul, PR. Ciência Florestal, Santa Maria, v. 14, n. 1, p. 67-76, 2004.

LOISELLE, B. A.; RIBBENS, E.; VARGAS, O. Spatial and temporal variation of seed rain in a Tropical Lowland Wet Forest. Biotropica, Marburg, v. 28, n. 1, p. 82-95, 1996.

LONGHI, S. J.; BRUN, E. J.; OLIVEIRA, D. M.; FIALHO, L. E. B.; WOJCIECHOWSKI, J. C.; VACCARO, S. Banco de sementes do solo em três fases sucessionais de uma Floresta Estacional Decidual, em Santa Tereza, RS. Ciência Florestal, Santa Maria, v. 15, n. 4, p. 359-370, 2005.

MCCUNE, B.; MEFFORD, M. J. PC-ORD: multivariate analysis of ecological data. Version 4. Gleneden Beach: MjM, 1999. $237 \mathrm{p}$.

MORENO, J. A. Clima do Rio Grande do Sul. Porto Alegre: Secretaria da Agricultura, 1961. 42 p.

Cerne, Lavras, v. 19, n. 4, p. 621-628, out./dez. 2013 
NARVAES, I. S.; BRENA, D. A.; LONGHI, S. L. Estrutura da regeneração natural em Floresta Ombrófila Mista na Floresta Nacional de São Francisco de Paula, RS. Ciência Florestal, Santa Maria, v. 15, n. 4, p. 331-342, 2005.

NASCIMENTO, A. R. T.; LONGHI, S. J.; BRENA, D. A. Estrutura e padrões de distribuição espacial de espécies arbóreas em uma amostra de Floresta Ombrófila Mista em Nova Prata, RS. Ciência Florestal, Santa Maria, v. 11, n. 1, p. 105-119, jan./fev. 2001.

NIMER, E. Clima. In: INSTITUTO BRASILEIRO DE GEOGRAFIA E ESTATÍSTICA. Geografia do Brasil: região Sul. Rio de Janeiro, 1990. p. 151-187.

PEIXOTO, A. L.; REITZ, R.; GUIMARÃES, E. F.

Monimiáceas. Itajaí: Herbário Barbosa Rodrigues, 2001. 64 p. (Flora Ilustrada Catarinense).

PINHEIRO, F.; RIBEIRO, J. F. Síndromes de dispersão de sementes em matas de galeria do Distrito federal. In: RIBEIRO, J. F.; FONSECA, C. E. L.; SOUZA-SILVA, J. C. (Ed.). Cerrado: caracterização e recuperação de Matas de Galeria. Planaltina: EMBRAPA, 2001. p. 335-375.

PIVELLO, V. R.; PETENON, D.; JESUS, F. M. de; MEIRELLES, S. T.; VIDAL, M. M.; ALONSO, R. A. S.; FRANCO, G. A. D. C.; METZGER, J. P. Chuva de sementes em fragmentos de Floresta Atlântica (São Paulo, SP, Brasil), sob diferentes situações de conectividade, estrutura florestal e proximidade da borda. Acta Botanica Brasilica, São Paulo, v. 20, n. 4, p. 845-859, 2006.

QUADROS, F. L. F. de; PILLAR, V. de P. Transições florestacampo do Rio Grande do Sul. Ciência \& Ambiente, Santa Maria, v. 1, n. 1, p. 109-118, 2002.

RIO GRANDE DO SUL. Secretaria Especial do Meio Ambiente. Inventário florestal contínuo do Rio Grande do Sul. Porto Alegre, 2002. 706 p. Relatório técnico.

Cerne, Lavras, v. 19, n. 4, p. 621-628, out./dez. 2013
RODERJAN, C. V.; GALVÃO, F.; KUNIYOSHI, Y. S.; HATSCHBACH, G. G. As unidades fitogeográficas do Estado do Paraná. Ciência \& Ambiente, Santa Maria, v. 24, n. 1, p. 75-92, 2002.

SANTOS, I. S.; PEIXOTO, A. L. Taxonomia do gênero Macropeplus Perkins (Monimiaceae, Monimioideae). Rodriguésia, Rio de Janeiro, v. 52, n. 81, p. 65-105, 2001.

SCHERER, C.; JARENKOW, J. A. Banco de sementes de espécies arbóreas em floresta estacional no Rio Grande do Sul, Brasil. Revista Brasileira de Botânica, São Paulo, v. 29, n. 1, p. 67-77, 2006.

SOBRAL, M.; JARENKOW, J. A.; BRACK, P.; IRGANG, B.; LAROCCA, J.; RODRIGUES, R. S. Flora arbórea e arborescente do Rio Grande do Sul. Porto Alegre: RimaNovoAmbiente, 2006. 350 p.

SOUZA, A. F.; FORGIARINI, C.; LONGHI, S. J.; BRENA, D. A. Regeneration patterns of a long-lived dominant conifer and the effects of logging in southern South America. Acta Oecologica, Paris, v. 34, p. 221-232, 2008.

SOUZA, V. C.; LORENZI, H. Botânica sistemática: guia ilutrado para identificação das famílias de Angiospemas da flora brasilera baseado em APG II. Nova Odessa: Instituto Plantarum, 2005. 639 p.

TABARELLI, M.; PERES, C. A. Abiotic and vertebrate seed dispersal in the Brazilian Atlantic Forest: implications for forest regeneration. Biological Conservation, London, v. 106, p. $165-176,2002$.

WIJDEVEN, S. M. J.; KUZZE, M. E. Seed availability as a limiting factor in forest recovery processes in Costa Rica. Restoration Ecology, Durham, v. 8, n. 4, p. 414-424, 2000 .

Recebido: 10 de janeiro de 2011; aceito: 24 de maio de 2013. 